\title{
MODELLING AND OPTIMISATION OF VACUUM COLLECTION SYSTEM FOR CRUISE SHIP KITCHEN GARBAGE
}

\author{
Du Jun \\ Li Ruonan \\ Wu Xin \\ Zhao Hang \\ Jiangsu University of Science and Technology, China
}

\begin{abstract}
Pollution of the marine environment by ship garbage is an urgent problem to be solved at home and abroad. The ship kitchen garbage vacuum collection system is a new environmental protection scheme for garbage disposal. It has many advantages, such as using a pipeline instead of manual operation, creating high-level sanitary conditions, realising completely closed garbage collection and transportation, eliminating cross-pollution, saving space and so on. In this paper, the system is modelled, and the calculation of pipeline pressure loss, the vacuum degree of the vacuum tank and the energy consumption of the system are briefly introduced. In order to reduce the energy consumption, an algorithm for the emptying and discharging port is presented. In order to solve the problem of optimising relevant parameters, the vacuum transport mechanism of garbage is studied based on an optimisation model of the pipe network, and the experimental platform of a simulation device is set up. In engineering, this is of great significance to the design of cruise ship garbage collection and treatment systems and the development of supporting technology.
\end{abstract}

Keywords: Kitchen waste vacuum collection; System modeling; Sorting algorithm; Model experiment

\section{INTRODUCTION}

In order to protect the marine environment and control the pollution of the marine environment by ships, the International Maritime Organization (IMO) has formulated the International Convention for the Prevention of Pollution from Ships. Kitchen garbage on board ships is the main component of organic domestic waste, which has the characteristics of high organic matter content, high moisture content, high salt and fat content, easy acidification and corruption, odour and so on. Therefore, the process of food waste collection and disposal, if not properly operated, is prone to environmental pollution and food safety problems. It is very important to choose the appropriate processing technology to reduce the cost of investment cost and operation and the potential eco-environmental risk of kitchen waste treatment, and so to preserve the marine environment by eliminating pollution from the release of oil and other harmful substances into the ocean and to minimise pollution from the accidental discharge of such substances [12] [19].

According to the requirements of IMO and numerous countries on pollutant emission control, no other solid waste shall be discharged, although kitchen waste can be crushed to less than $25 \mathrm{~mm}$ or discharged directly under limited conditions [8]. However, due to the limited overall resources of ships, the disposal of solid waste, especially the implied reduction of capacity, has an important role in the pollution control of ships. At present, the commonly used treatment 
methods include incineration, packaging and storage, comminution and discharge. In order to reduce the tank capacity required and prolong the storage time of solid waste, it is generally crushed, dehydrated, dried and sterilised before packing and storing, and then compressed and packaged.

The kitchen waste vacuum collection system is a new environmental protection scheme that uses vacuum transportation to deal with organic waste. When the waste is put into place and broken by a crusher, it falls into a garbage transfer box, then transported to the garbage storage bin through a vacuum collection pipe, compressed and packaged and sent to the incineration storage bin for treatment. The waste gas from incineration is cleaned up to the standard by flue gas desulphurisation and denitrification technology [3] [4][17], and then discharged as shown in Fig. 1. In this way, on the one hand,it can play the effect of the equipment as much as possible according to the characteristics of garbage;on the other hand, it can also effectively realise the recycling of garbage, at the same time as prolonging the storage time of garbage to a certain level and reducing the storage space required.

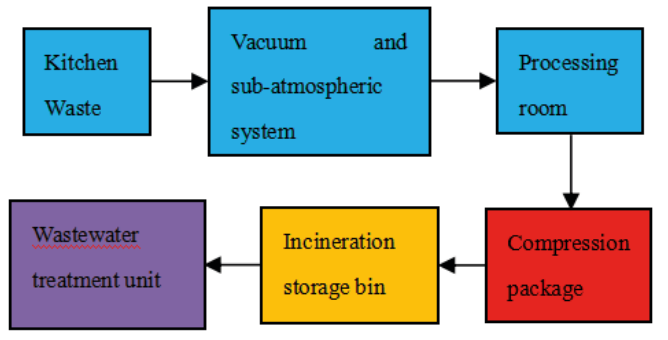

Fig. 1. Flow chart of garbage collection and treatment system

The vacuum collection system consists of a valve system, piping system, separation system, vacuum power system and compression system. As shown in Fig. 2, the working principle is that a negative pressure machine is installed at the end of the collection system. When this equipment is operated, negative pressure is formed in the whole system, resulting in a pressure difference between the inside and outside of the pipe, and the air is drawn into the pipe. At the same time, the waste is drawn into the pipe by air and transported to the separator, where it is separated from the air; the separated waste is discharged from the unloader, and the air is sent to the dust collector for purification and then discharged.

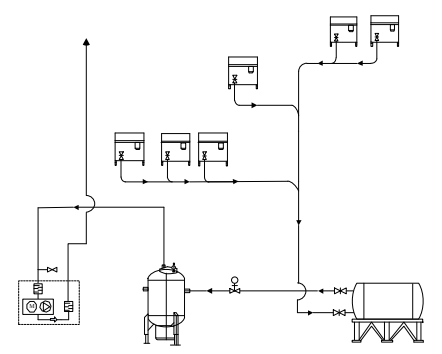

Fig. 2. Schematic diagram of vacuum collection system for cruise kitchen garbage

\section{ANALYSIS OF MOTION MECHANISM OF FOOD WASTE PARTICLES IN THE SYSTEM}

\section{VACUUM DRYING EFFECT}

The drying effect caused by the vacuum and compression conditions can reduce the moisture content in food waste and thus reduce its weight. This dehydration phenomenon is mainly due to the decrease of relative humidity caused by the change of pressure. The water vapour contained in the air depends on the temperature and pressure, and can be described by calculation and relative humidity.

The specific humidity is the ratio of water vapour mass to dry air mass in a given volume of mixture, represented as Eq. (1) and Eq. (2).

$$
\begin{gathered}
\omega=\frac{\mathrm{m}_{\mathrm{v}}}{\mathrm{m}_{\mathrm{a}}} \\
\omega=\frac{622 \mathrm{p}_{\mathrm{v}}}{\mathrm{p}-\mathrm{p}_{\mathrm{v}}}
\end{gathered}
$$

where: $m_{v}$ is the mass of steam, $g$,

$\mathrm{m}_{\mathrm{a}}$ is the air quality, $\mathrm{kg}$.

Because the volume flow in the kitchen garbage vacuum collection system is isolated from the atmosphere, regardless of the temperature or pressure, the specific humidity throughout the pipe is equal. The relative humidity is the ratio of the partial pressure of water vapour to the partial pressure of the vapour when the air is saturated at the same temperature. It is usually expressed as a percentage, and $100 \%$ represents saturated air, represented as Eq. (3).

$$
\phi=\frac{\mathrm{p}_{\mathrm{v}}}{\mathrm{p}_{\mathrm{g}}}
$$

where: $p_{v}$ is the actual pressure of the water vapour;

$\mathrm{p}_{\mathrm{g}}$ is the actual pressure of water vapour in saturated air.

Combined with the above-mentioned formulas for specific humidity and relative humidity, the general equation for specific humidity is given in Eq. (4).

$$
\omega=\frac{622 \phi \mathrm{p}_{\mathrm{g}}}{\mathrm{p}-\phi \mathrm{p}_{\mathrm{g}}}
$$

The lower the relative humidity between the dry air and the material in the pipe, the greater the drying effect is when the wet granular material is transported in vacuum. 


\section{RESISTANCE OF MOVING SPHERICAL OBJECTS}

In the vacuum transport process, the equivalent diameter is used to represent the particle size of a single particle, converting irregular particles into spheres of equal mass, The diameter of this sphere is that of irregular particles $\left(\mathrm{d}_{\mathrm{e}}\right): \mathrm{d}_{\mathrm{e}}=1.24\left(\frac{\mathrm{m}_{\xi}}{\rho_{\xi}}\right)^{\frac{1}{3}}$ where $\mathrm{m}_{\xi}$ is the particle mass $(\mathrm{kg})$. The particle size of broken kitchen garbage is determined by the particle size $d_{s}$ of the crusher, the bulk weight size of broken garbage is $1.045 \times 10^{3} \mathrm{~kg} / \mathrm{m}^{3}$, the viscosity of broken and mixed kitchen garbage is $1.807 \mathrm{~Pa} \cdot \mathrm{s}$, and the mass of individual particles is: $\mathrm{m}=\frac{4}{3} \pi \rho \mathrm{r}^{3}$.

The total quality of once-in-one collection of kitchen garbage is known is $\mathrm{M}$. Then, combined with the mass of a single particle, the number of solid waste particles can be calculated as: $\mathrm{n}=\frac{M}{\mathrm{~m}}$.

The equivalent diameter is $\frac{\pi}{6} \mathrm{~d}_{\mathrm{e}}{ }^{3} \cdot \rho_{\xi} \cdot n=m_{n}, d_{e}=1.24\left(\frac{m_{n}}{\rho_{\xi} n}\right)^{\frac{1}{3}}$.

The gas-solid mixing ratio can also be obtained.

The kitchen garbage particles are driven by airflow and can be described by the resistance of moving spherical objects. The known resistance to the movement of a spherical object in a stationary fluid is as in Eq. (5):

$$
F_{R}=C_{D} \times \alpha_{\mathrm{s}} \times \rho \times \frac{\mathrm{v}^{2}}{2}
$$

where: $F_{R}$ is resistance of the fluid in motion, N;

$C_{D}$ is a resistance coefficient, dimensionless;

$\alpha_{\mathrm{s}}$ is the projected area of the object, $\mathrm{m}^{2}$;

$\rho$ is the fluid density; at $20^{\circ} \mathrm{C}$ the air density is $1.205 \mathrm{~kg} / \mathrm{m}^{3}$;

$\mathrm{V}$ is the relative velocity of motion, $\mathrm{m} / \mathrm{s}$.

\section{SYSTEM MODELLING}

The dynamic characteristics of the kitchen waste vacuum collection system include the relationship between the local pressure, transportation velocity, emptying time and so on. The dynamic characteristics are the key factors to master the operation law and optimise the system. The characteristics of the fluid flow in the pipeline are analysed, and the thermodynamic model of the system is established by means of engineering thermodynamics and fluid mechanics [2] [5] [10].

\section{PIPE NETWORK SYSTEM DESCRIPTION}

A vacuum collection pipe network on a cruise ship usually consists of several main pipelines, each of which is laid out in a tree topology, and each main pipe has an upper and a lower end node. Generally, there are many branches flowing into the pipe at different points between the nodes at both ends of each main pipe. In order to simplify the calculation, it is necessary to number the pipe segments and nodes of the pipe network. Restaurants and kitchens on different decks have multiple dump ports and are connected to a single plumbing system. The whole pipe network is composed of different discharge ports, vacuum valves, straight pipe segments, bending pipe segments, etc. The pipe network system is established as follows:

a. The entire pipe network system consists of three parts: baseline, branch, and sub-branch, The pipe on the deck layer of the vacuum pump station on the cruise ship is defined as the baseline, which is represented by the symbol L. The vertical pipe between the deck layer of the vacuum pump and the kitchen on the upper deck is defined as a branch, denoted by the symbol S. The pipe connecting the deck layer pipe and the drop unit where the kitchen is located is defined as a sub-branch $\mathrm{N}$.

b. The different input ports are represented as $\mathrm{U}_{i}$, where $i$ ndicates the corresponding release port numbers.

c. Each discharge port is controlled by a vacuum valve. The opening and closing of the vacuum valve causes a pressure difference and a certain flow rate to form between the outside world and the pipe network.

\section{PRESSURE LOSS CALCULATION}

The pressure loss of kitchen garbage in steady conveying state is related to the physical properties and mixing ratio of the material. The energy required in the process of food waste transportation is mainly consumed by the pressure loss caused by the movement of air and kitchen waste in the conveying pipe. The pressure loss formula can be expressed as Eq. (6) and Eq. (7):

$$
\Delta P_{\mathrm{m}}=\alpha \Delta P_{\alpha}=(1+\beta \mathrm{m}) \Delta P_{\alpha}
$$

$$
\Delta P_{\alpha}=\lambda_{\alpha} \frac{L_{\mathrm{eg}}}{D} \cdot \frac{\rho_{\alpha}}{2} v_{\alpha}^{2}
$$

In the formula, $\alpha=\Delta P_{\mathrm{m}} / \Delta P_{\alpha}$ represents the ratio of the pressure loss in the material being conveyed to the pressure loss in pure air flow in the same pipe, referred to as the pressure loss ratio. $\alpha$ varies with the physical properties of the material being conveyed. For the same material, it is generally related to the mixing ratio. When the mixing ratio is the same, when we take $v_{\mathrm{a}}$ as a big value, $\alpha$ is a small value. This is because the suspension is more uniform. $\beta$ is the coefficient related to the physical properties of the material, generally taken as $0.38 \sim 0.65 . \lambda_{\alpha}$ is the pipe friction coefficient of pure gas flow, according to $R_{\mathrm{e}}$ and the wall roughness of the conveying pipe used $\varepsilon / D$. The equivalent length of the conveying pipe $L_{\text {eg }}$ be expressed as Eq. (8): 


$$
L_{\mathrm{eg}}=L_{\mathrm{h}}+R L_{\mathrm{v}}+\delta D\left(\theta_{1}+\theta_{2}+\ldots+\theta_{\mathrm{n}}\right) / 90^{\circ}
$$

In the formula, $\mathrm{L}_{\mathrm{h}}$ is the horizontal tube length, $\mathrm{L}_{\mathrm{v}}$ is the vertical tube length, $\mathrm{n}$ is the pipe number (the corresponding angle is $\theta), \delta, \mathrm{R}$ is a coefficient.

\section{VACUUM DEGREE}

When the kitchen garbage is collected into the vacuum tank, the average pressure in the vacuum tank rises. The process of air compression can be approximately quasi-static, and the gas in the vacuum tank can be described by the gas equation of state as follows in Eq. (9):

$$
\frac{d p}{d t} \cdot v+\frac{\mathrm{d} v}{d t} \cdot p=m R \frac{d T}{d t}
$$

The air volume in the vacuum tank varies according to the volume flow rate of the liquid, as follows in Eq. (10):

$$
\frac{\mathrm{dv}}{\mathrm{dt}}=-C_{d} \cdot A_{v a l} \cdot \sqrt{\frac{2 \Delta p_{v a l}}{\rho_{w}}}
$$

For the convenience of research, the pressure can be expressed as vacuum degree $p_{v}$ as follows in Eq. (11) :

$$
p_{v}=p_{0}-p
$$

In the formula, $p_{0}$ is normal atmosphere with the value of $101.325 \mathrm{kPa}$; $\mathrm{P}$ is the pressure within the system, $\mathrm{kPa}$.

\section{SIMULATION OF EMPTYING ALGORITHM FOR DISCHARGE PORT}

\section{OBJECT FUNCTION}

The factor that directly affects the economy of the kitchen garbage transportation network is the energy consumption during operation of the system. Therefore, we take the energy consumption of the system as the objective function, which depends on the emptying sequence selected in the current time period and the air velocity $\mathrm{V}_{\mathrm{t}}$ of the system. During stable operation of the system, the air is compressible relative to the pressure, and the conveying speed will vary along the length of the whole pipe. Therefore, assuming that the transportation velocity of theh kitchen waste in the pipeline is a constant value of $\mathrm{V}_{\mathrm{t}}$ the energy consumption is optimised by adopting a reasonable emptying strategy. In order to maintain the vacuum required by the system during the vacuum collection of kitchen waste, the calculation formula of energy consumption by the vacuum pump is as follows in Eq. (12):

$$
E_{\text {total }}=W_{\mathrm{p}}+E_{\mathrm{st}}
$$

where: $E_{\text {total }}$ is the total energy consumption generated by the system in a set of emptying sequences, $\mathrm{kJ}$;

$W_{\mathrm{p}}$ is the energy consumption generated by the vacuum pump in the vacuum pumping of the system, kJ;

$E_{\text {st }}$ is the energy consumption generated by the system during the stable phase of emptying the kitchen garbage, kJ.

Before transporting the kitchen garbage, the vacuum pump is needed to pump the whole system. Calculation of the energy consumption in the pumping process is as follows in Eq. (13):

$$
W_{\mathrm{p}}=\mathrm{w}_{\mathrm{p}} \mathrm{t}_{\mathrm{p}}
$$

where: $\mathrm{W}_{\mathrm{p}}$ is the power of the vacuum pump, $\mathrm{kW}$;

$\mathrm{t}_{\mathrm{p}}$ is the time it takes for the vacuum pump to pump a vacuum, $s$

The vacuum degree required by the vacuum collection system for kitchen waste is in the range of $0.2 \mathrm{kPa}-101 \mathrm{kPa}$ and the pumping time is calculated according to the crude vacuum. The pumping time of the vacuum pipe can pass through the initial pressure $P_{0}$, the vacuum required by the system $P_{1}$, the speed of evacuation $S_{\mathrm{e}}$ and volume $V$, as follows in Eq. (14) and ,Eq. (15):

$$
V=\frac{\pi}{4} \mathrm{~d}^{2} \cdot L_{e g}
$$

$$
\mathrm{t}_{\mathrm{p}}=\frac{V+V_{p o t}}{S_{e}} \times 2.303 \times \log _{10}\left(\frac{P_{0}}{P_{1}}\right)
$$

where: $d$ is the vacuum pipe diameter, $m$;

$P_{0}$ is the initial pressure (atmospheric pressure), $\mathrm{kPa}$;

$P_{1}$ is the pressure required by the system, $\mathrm{kPa}$;

$V$ is the system vacuum chamber volume, $\mathrm{L}$;

$S_{\mathrm{e}}$ is the actual rate of pumping, $\mathrm{L} / \mathrm{min}$. (Taking into account the bottleneck effect of ducts and valves, the actual pumping velocity is estimated to be $80 \%$ of the theoretical pumping rate.)

Once the transition phase ends and reaches a steady air speed $V_{t}$, the system is at a stable stage ready to discharge kitchen garbage. The energy consumption in the process of kitchen transportation is directly related not only to time but also to the path of transporting kitchen garbage air $l\left(T_{i}^{A}\right)$. The calculation of energy consumption for the stabilisation phase of the system[6] is as follows in Eq. (16):

$$
E_{\mathrm{st}}=\left[\mathrm{A}+\mathrm{B} \cdot l\left(T_{i}^{A}\right)\right] \cdot T_{t}^{s t}
$$


where: $\mathrm{A}, \mathrm{B}$ is the kitchen garbage correlation coefficient; $T_{t}^{s t}$ is the time of discharging a group of sequences in the stable operation stage.

Assuming that, at the beginning of the time period $t$, the kitchen garbage share of $U_{\mathrm{i}}$ is $L_{\mathrm{i}}$, then the energy consumption of the system depends on the emptying order of the delivery unit. Given the region $S$ that needs to be emptied at the current time $t$, a valid vacuuming sequence $\varepsilon_{\mathrm{t}}=\left[U_{1}, U_{2}, \cdots\right]$ is an ordered subset of the input port set. The emptying operation of a set of emptying sequences to achieve kitchen waste discharge is divided into two steps. The first step is to empty the transportation pipe connected to the drop port; the second step is to transport the kitchen garbage in the pipe network. If and only if the emptying port is upstream of the position of the transported kitchen garbage, the transportation of the garbage and the emptying operation of the next one can overlap in time. Under this assumption, given the current emptying sequence $\varepsilon_{\mathrm{t}}$ and input load $L_{\mathrm{i}}$, the time required to perform a set of emptying sequences in the stabilisation phase $\varepsilon_{\mathrm{t}}$ is as follows in Eq.(17) and Eq. (18):

$$
\begin{gathered}
\mathrm{T}_{\mathrm{t}}^{\mathrm{st}}=\sum_{\substack{U_{\mathrm{i}} \in \mathcal{\varepsilon}_{\mathrm{t}} \\
U_{\mathrm{j}}=\operatorname{next}\left(U_{\mathrm{i}}\right)}} \mathrm{T}_{\mathrm{t}}^{\mathrm{st}}(\mathrm{i}, j) \\
T_{\mathrm{t}}^{\mathrm{st}}(\mathrm{i}, \mathrm{j})=C_{1,{ }_{\mathrm{t}} \mathrm{st} \mathrm{t}}^{\mathrm{st}}+\frac{l\left(T_{\mathrm{i}}^{E}\right)-l\left(T_{\mathrm{i}}^{E} \cap T_{\mathrm{j}}^{E}\right)}{\mathrm{v}_{\mathrm{t}}}
\end{gathered}
$$

where: $l\left(T_{\mathrm{i}}^{E}\right)$ is kitchen garbage from the outlet $U_{\mathrm{i}}$ to the root node that go through the path;

next $\left(U_{\mathrm{i}}\right)$ is the post-release port of $\mathrm{Ui}$ in the ordered sequence $\varepsilon_{\mathrm{t}}$;

$T_{\mathrm{t}}^{\mathrm{st}}(\mathrm{i}, \mathrm{j})$ is the total time spent emptying the vent $U_{\mathrm{i}}$.

\section{EXAMPLES}

Fig. 3 shows an example of a pipe network system with six entrances. Suppose at some point $t$ that the liquid levels in the discharge ports $\mathrm{U}_{1}, \mathrm{U}_{3}, \mathrm{U}_{4}, \mathrm{U}_{5}, \mathrm{U}_{6}$ meet the discharge standard.

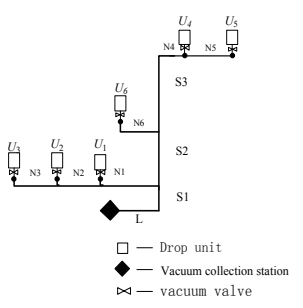

(a) Typical examples

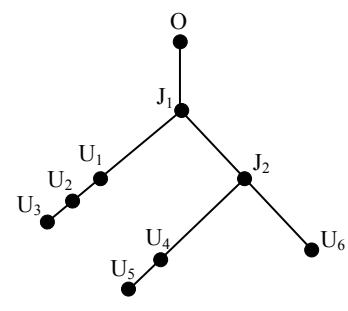

(b) B binary tree model of the example
Fig. 3. Pipe network system example

The values of the parameters are as follows:

The speed of kitchen garbage in the pipe $\mathrm{v}=18 \mathrm{~m} / \mathrm{s}$; mixing ratio $\mathrm{m}=5$; material physical property correlation coefficient $\beta=0.6$; pipe friction coefficient $\lambda_{\alpha}=0.024$; gas density in pipe $\rho_{\alpha}=1.2 \mathrm{~kg} / \mathrm{m}^{3}$; flow rate of three-leaf Roots blower $\mathrm{q}=2.51 \mathrm{~m}^{3} / \mathrm{min}$; volume of vacuum tank $2000 \mathrm{~L}$; power of motor $w_{p}=4 \mathrm{~kW}$. The process of emptying kitchen garbage from sub-branch pipes is assumed to be time-consuming, $5 \mathrm{~s}$.

Tab. 1. Pipe network parameters

\begin{tabular}{|c|c|c|c|}
\hline Route number & $\begin{array}{c}\text { Tube diameter } \times \\
\text { wall thickness/mm }\end{array}$ & $\begin{array}{c}\text { Length of } \\
\text { pipeline } / \mathbf{m}\end{array}$ & $\begin{array}{c}\text { Pipe section } \\
\text { pressure loss/Pa }\end{array}$ \\
\hline root- $\mathrm{J}_{1}$ & $100 \times 4$ & 12 & 4478.98 \\
\hline $\mathrm{J}_{1}-\mathrm{U}_{1}$ & $100 \times 4$ & 20 & 7464.96 \\
\hline $\mathrm{U}_{1}-\mathrm{U}_{2}$ & $100 \times 4$ & 3 & 1119.76 \\
\hline $\mathrm{U}_{2}-\mathrm{U}_{3}$ & $100 \times 4$ & 4 & 1493 \\
\hline $\mathrm{J}_{1}-\mathrm{J}_{2}$ & $100 \times 4$ & 15 & 5598.72 \\
\hline $\mathrm{J}_{2}-\mathrm{U}_{4}$ & $100 \times 4$ & 17 & 6345.20 \\
\hline $\mathrm{U}_{4}-\mathrm{U}_{5}$ & $100 \times 4$ & 5 & 1866.24 \\
\hline $\mathrm{J}_{2}-\mathrm{U}_{6}$ & $100 \times 4$ & 9 & 3359.24 \\
\hline
\end{tabular}

Calculations are made using java. In the pipe network example, the discharge ports are ordered into a queue. When the discharge sequence of the kitchen garbage collection system is varied, the energy consumption of the system under each emission sequence is different in terms of economy. In this example, the minimum energy consumption of U5->U4->U6 ->U3 ->U2 ->U1 ->root was $1523.1 \mathrm{~kJ}$.

\section{EXPERIMENTAL RESEARCH}

\section{EXPERIMENTAL STEPS AND METHODS}

The kitchen garbage experimental system is shown in Fig. 4.

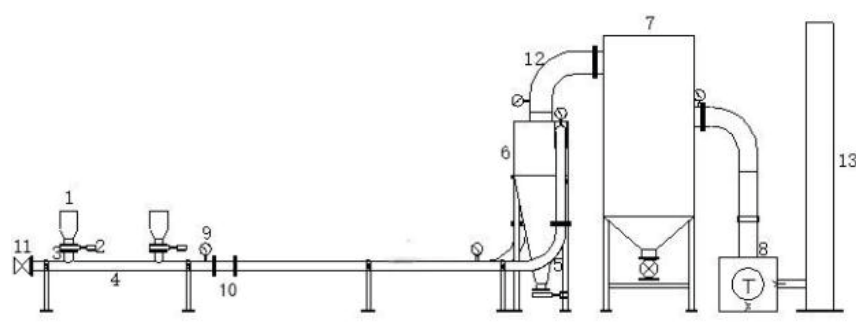

1 discharge port; 2 electric plug-in valve; 3 drop joint pipe and flange; 4 pipes (including connecting flanges); 5 elbows (including flanges); 6 separator; 7 bag filter; 8 unit (variable frequency); 9 electric contact vacuum pressure gauge; 10 transparent PVC pipe; 11 sluice valve; 12 deviceto-device connection pipe; 13 exhaust funnel

Fig. 4. System diagram of experimental equipment for kitchen waste

(1) Set up the experimental equipment according to Fig. 4.

(2) In advance, divide the kitchen garbage into two groups: table ping-pong balls and potato (prepared into particles). The diameter of the particles was recorded as $\mathrm{ds}(\mathrm{mm})$, and weighed on $\mathrm{m}(\mathrm{kg})$.

(3) Check each valve, the pipe pressure, and whether the vacuum degree is as required or not.

(4) Open control valve 2 for kitchen garbage collection. The proper amount of garbage is collected into separator 6 through a PVC pipe with inner diameter $100 \mathrm{~mm}$. 
During this process, the reading of electric contact pressure gauge 9 is recorded, and the flow state of particles in the transparent PVC pipe 10 is photographed by highspeed camera.

(5) Garbage and air are realised in separator 6. The gas is further filtered from pipe 12 into the dust collector bag 7 to meet the air inlet requirement of vacuum unit 8 . Finally, the gas is discharged into the atmosphere through the exhaust tube 13 .

(6) Measuring the total transparent PVC pipeline length $\mathrm{L}_{\text {all }}$, the kitchen garbage enters the PVC pipeline at a time of $t_{0}$, and leaves the PVC pipe at $t_{1}$.The speed of the kitchen garbage can be determined by $\frac{\mathrm{L}_{\text {all }}}{\mathrm{t}_{1}-\mathrm{t}_{0}}$.

(7) The rotor speed of the vacuum unit is changed by the frequency converter, the air volume in the pipe is controlled by the flowmeter, and the velocity of the waste is kept constant at the discharge port. In various cases, the electrical contact pressure gauge 9 readings are recorded and close attention is paid to the flow status of kitchen garbage particles in the transparent PVC pipe 10.

\section{ROOTS BLOWER}

As shown in Fig. 5, as the frequency of the Roots blower increases, the pressure decreases, and the closer it is to a vacuum, the velocity of the particles seen through the observation window gradually increases, and the time is gradually decreasing.

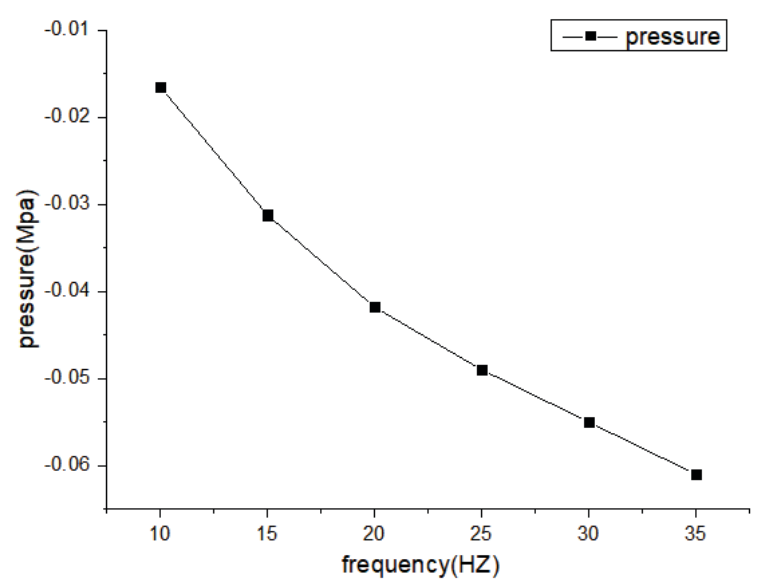

Fig. 5. Pressure and frequency diagram of Roots blower

When transporting ping-pong balls, as shown in Fig. 6, at a frequency of $10 \mathrm{~Hz}$, the pressure is $-0.0165 \mathrm{MPa}$. At this point, the balls are not fully transported to the end of the device. When the frequency increases to $25 \mathrm{~Hz}$, some of the balls break.

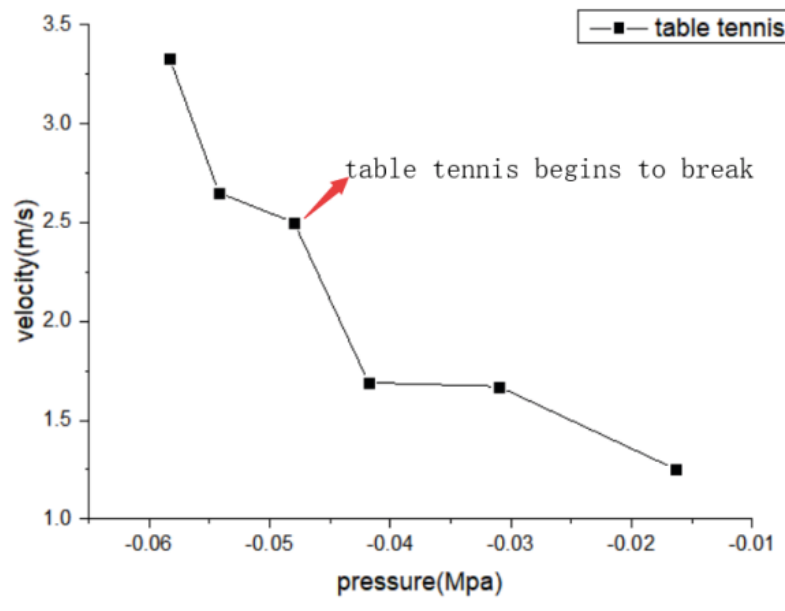

Fig. 6. Ping-pong balls pressure and velocity chart

When transporting potato particles, as shown in Fig. 7, at frequency $10 \mathrm{~Hz}$, the pressure is $-0.0165 \mathrm{MPa}$.At this point, the pressure is not enough to fully transport the potatoes, and at the observation window only a small number of particles pass through. When the frequency increases to $15 \mathrm{~Hz}$, the number of potato pieces passing through increases slightly, but they do not succeed in reaching the end of the pipe. When the frequency is $20 \mathrm{~Hz}$, most of the potato can be transported out of the equipment and the system becomes stable. When the frequency is $35 \mathrm{~Hz}$, the amount of potato remaining is $0.3 \mathrm{~kg}$, and the consumption of $0.15 \mathrm{~kg}$ is the evaporation of water in the potato.

As shown in Fig. 8, from the comparison of the speed at which the table tennis balls and potato are transported by the Roots blower, it can be seen that the changing trend of the two tracks is basically similar, The comparison shows that the experimental data obtained by using potato as the transported material are effective.

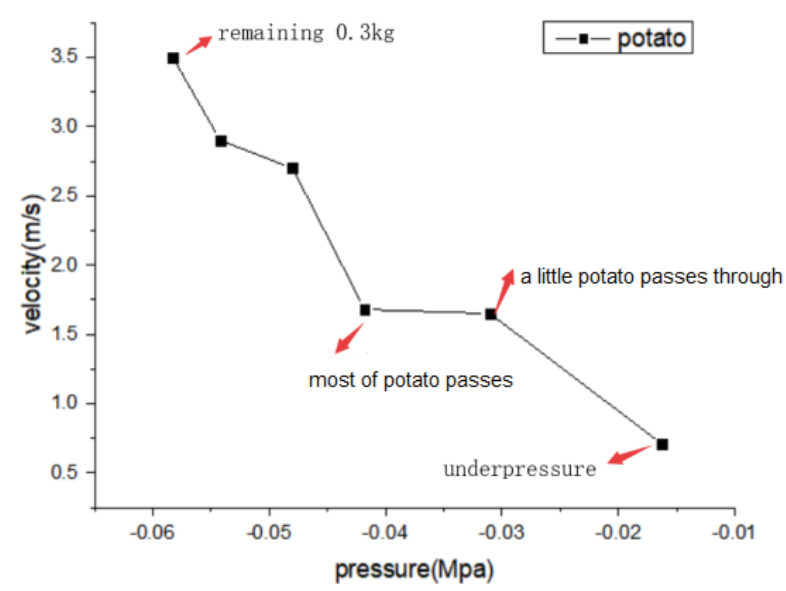

Fig. 7. Potato pressure and velocity chart 


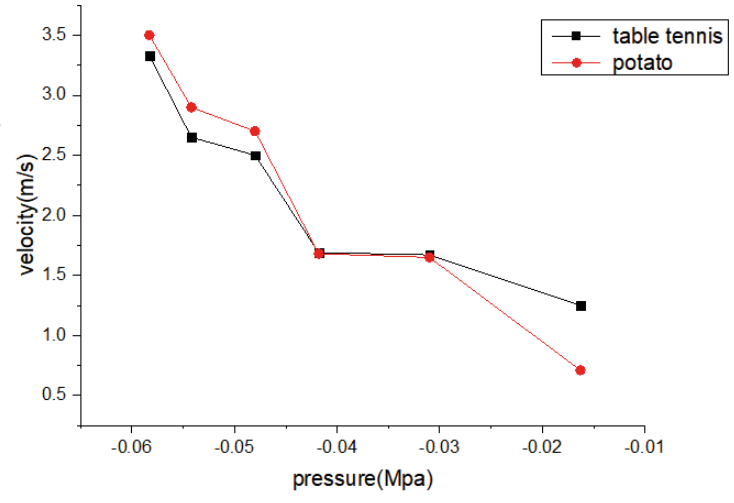

Fig. 8. Comparison of speed of table ping-pong balls and potato

Fig. 9 shows the observation window in the initial and final states. The contrast clearly shows the presence of water on the window. This also proves the vacuum drying effect in the above theory. When the temperature in the pipe reaches or exceeds the evaporation temperature under the corresponding saturated vapour pressure, the moisture in the particulate matter is evaporated.

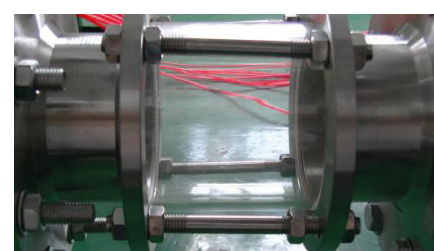

(a) Initial PVC pipeline image

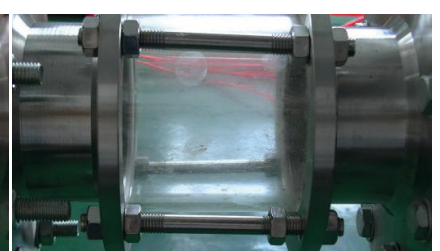

(b) Final PVC pipeline image
Fig. 9. Comparison of observation window at the beginning and end

\section{ROOTS VACUUM PUMP}

As shown in Fig. 10, with the increasing frequency of the Roots vacuum pump, the lower the pressure is, the closer it is to a vacuum. The velocity of particles through the observation window increases and the time decreases.

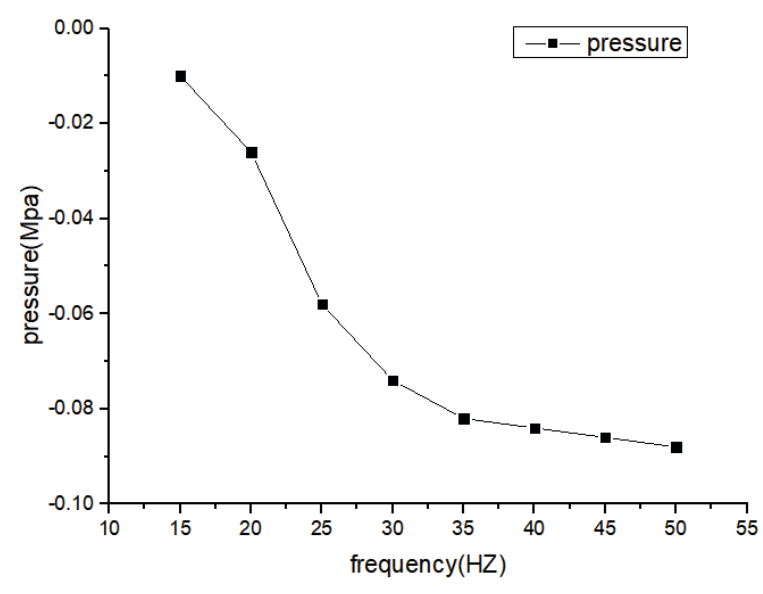

Fig. 10. Pressure and frequency diagram of Roots vacuum pump
When transporting table tennis balls, as shown in Fig. 11, when the frequency is $15 \mathrm{~Hz}$, the pressure is $-0.01 \mathrm{MPa}$, and the balls are not completely transported to the end of the equipment. They take longer to pass through the observation port. When the frequency increases to $25 \mathrm{~Hz}$, however, the balls can be successfully transported.

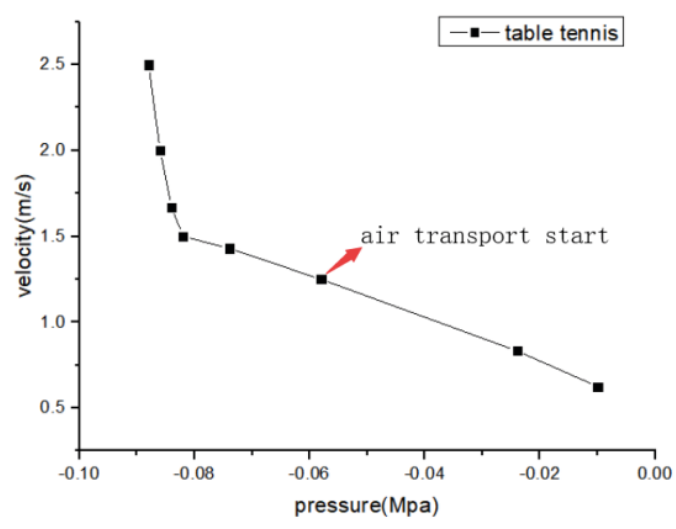

Fig. 11. Ping-pong balls pressure and velocity chart

In the previous group of ping-pong balls experiments, air transport began at $25 \mathrm{~Hz}$, so the initial frequency of the potato experiment was set as $25 \mathrm{~Hz}$, the pressure was $-0.058 \mathrm{MPa}$, and the initial weight was $0.8 \mathrm{~kg}$. As shown in Fig. 12, when the frequency is $25 \mathrm{~Hz}$, the pressure is not enough and the potato pieces do not pass through to the end of the device. If the frequency increases to $30 \mathrm{~Hz}$, and the initial weight is $0.8 \mathrm{~kg}$, the presence of water can be seen in the observation window, indicating that at this frequency and pressure, the water begins to evaporate and $0.6 \mathrm{~kg}$ of the potato comes out at the end. Keeping the $0.6 \mathrm{~kg}$ of potato in the device, and increasing the frequency to $35 \mathrm{~Hz}$, more water can be seen in the observation window, under this frequency and pressure. With the evaporation of a large amount of water, $0.35 \mathrm{~kg}$ of potato remains. Keeping the $0.35 \mathrm{~kg}$ of potato in the device and increasing the frequency to $40 \mathrm{~Hz}$, more water evaporates and $0.1 \mathrm{~kg}$ comes out at the end. And $0.8 \mathrm{~kg}$ of potato is first put in and $0.3 \mathrm{~kg}$ comes out at the end. When the frequency reached $50 \mathrm{~Hz}$, with $0.5 \mathrm{~kg}$ of potato initially put into the equipment, $0.3 \mathrm{~kg}$ came out at the end. Most of the potato pieces had evaporated into small particles.

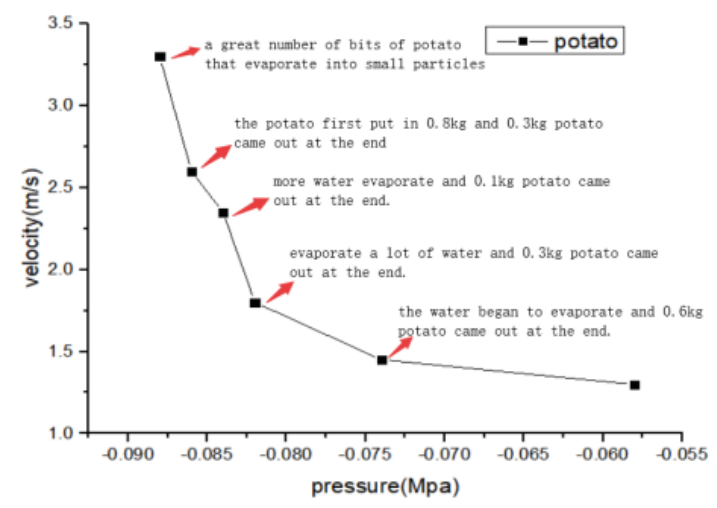

Fig. 12. Potato pressure and velocity chart 
As shown in Fig. 13, from the comparison of the speed of the table tennis balls and potato transported by the Roots vacuum pump, The comparison shows that the experimental data obtained by using potato as a transport material are effective.

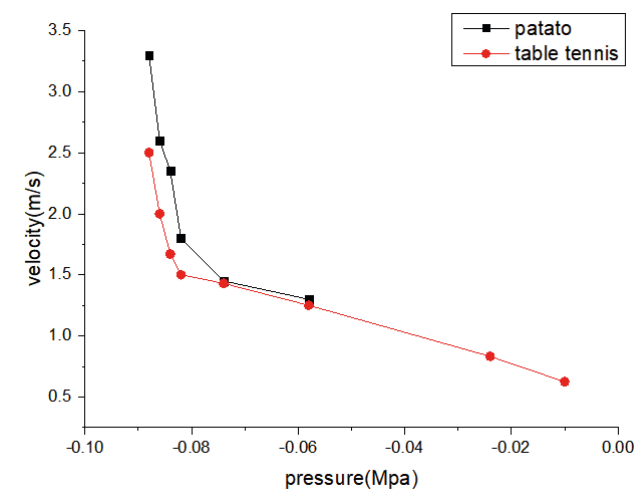

Fig. 13. Comparison of speed of ping-pong balls and potato

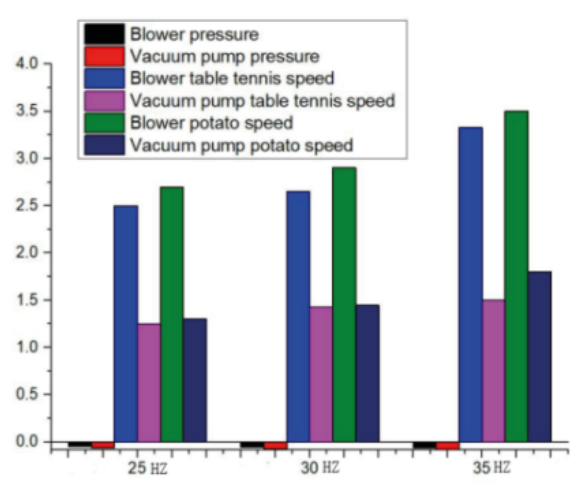

Fig. 14. $25 \mathrm{~Hz}, 30 \mathrm{~Hz}, 35 \mathrm{~Hz}$ state contrast diagram

Fig. 14 shows the vacuum degree of the Roots blower and vacuum pump at $25 \mathrm{~Hz}, 30 \mathrm{~Hz}$, and $35 \mathrm{~Hz}$. The transport velocity of the table tennis balls in the Roots blower and vacuum pump at different frequencies, and that of the potato were compared. As can be seen, the Roots vacuum pump can achieve a higher vacuum degree than the blower, with an increase of about $20 \%$. At the same frequency, although the Roots vacuum pump produces a high degree of vacuum, the speed of transport of the table tennis balls and potato pieces is not as high as that with the Roots blower, with a difference of nearly $50 \%$. But the blower has limitations and cannot achieve a high vacuum. So in the actual vacuum transportation, for systems needing a low vacuum degree and transporting material with low moisture content, the Roots blower can be chosen. However, the Roots vacuum pump is more suitable for a high vacuum degree, and high moisture content of the garbage for transportation.

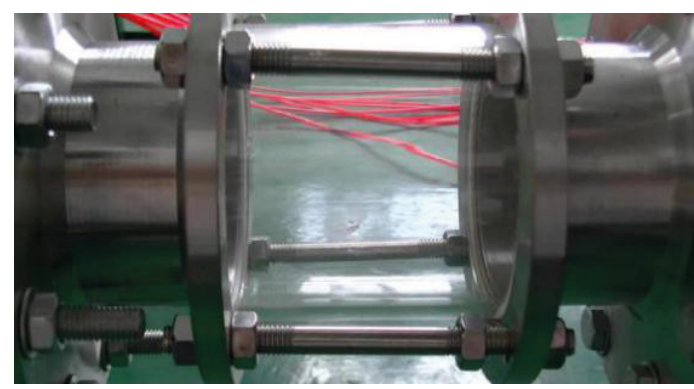

Fig. 15. Initial state at observation window

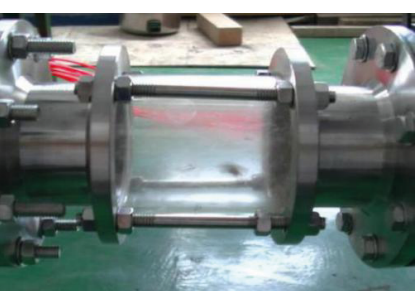

(a) PVC pipe at $25 \mathrm{~Hz}$

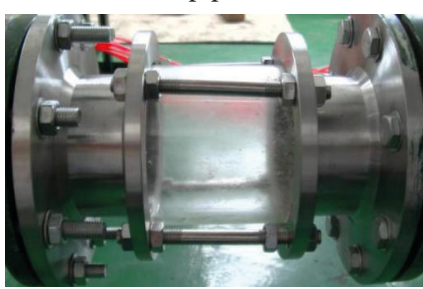

(c) PVC pipe at $35 \mathrm{~Hz}$

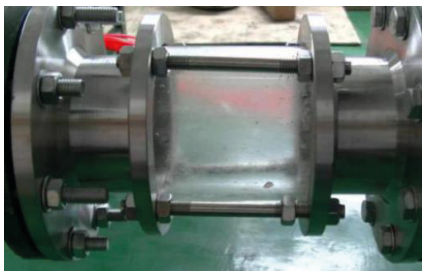

(e) PVC pipe at $45 \mathrm{~Hz}$

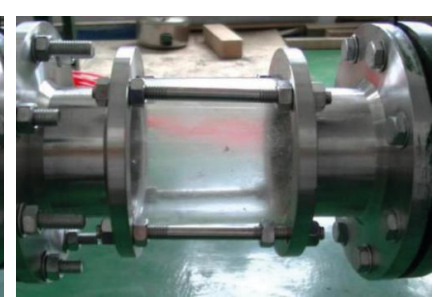

(b) PVC pipe at $30 \mathrm{~Hz}$

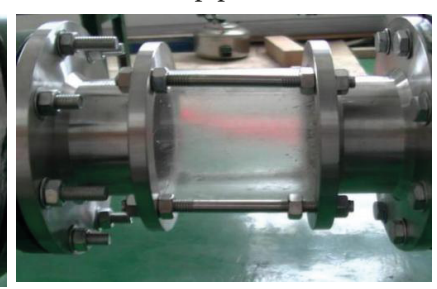

(d) PVC pipe at $40 \mathrm{~Hz}$

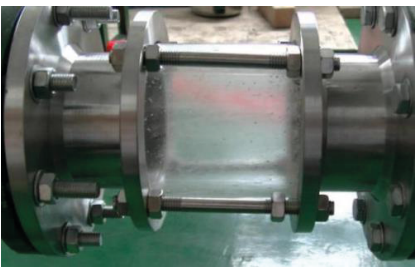

(f) PVC pipe at $50 \mathrm{~Hz}$
Fig. 16. Observation window images of final state at different frequencies

Fig. 15 and Fig. 16 show that the larger the vacuum degree is, the more obvious the evaporation of water is, comparing the variation of the observation window in the initial state and the various frequencies using the Roots vacuum pump. This also proves the drying effect of the vacuum pipe in the above theory. When the temperature in the pipe reaches or exceeds the evaporation temperature under the corresponding saturated steam pressure, the water completely evaporates, so the moisture in the garbage does not need to be considered.

\section{DISCUSSION}

Cèsar Fernández and others developed a model in 2014 using constraint programming technology to arrange the emptying sequence of a daily litter drop in order to minimise energy consumption [7]. But these applications are mainly aimed at living areas on land, and for marine areas the domestic application of this technology is not yet mature. 
Foreign sailing boats, high-speed passenger rolling ships, cruise ships and so on mainly use the Swedish Envac system, but the company only provides products, and the technology is confidential. At present, the vacuum collection of domestic cruise kitchen garbage is a new engineering technology, and the selection of key equipment such as the vacuum pump, vacuum storage tank and the optimisation of basic parameters, such as the vacuum degree and mixed conveying ratio, are still not perfect. As the vacuum sewage system becomes larger and more complex, the calculation of pressure loss, the design flow rate, vacuum degree and pipe diameter of the pipe network system must be optimised. Understanding the flow law of particle groups from a more comprehensive angle with the help of experiments [1][9][11][13-16][18][20] and strengthening the research on these problems will undoubtedly improve the reliability and economy of the system.

\section{CONCLUSIONS}

(1) Using the structure principle of a binary tree for reference, the pipeline network of a cruise ship's vacuum collection system is modelled as a binary tree and aerodynamic calculation is carried out. If the left and right sub-trees of a binary tree are to be emptied, the length of these subtrees will be compared. When the left sub-tree is longer, all the input ports on that sub-tree will be arranged in the order of distance and proximity, and when the left tree is longer,it should be arranged in order from far to near. Otherwise, arrange all the outlets on the right sub-tree that meet the emission requirements. If there is an input port in the fork of the tree, the nodes except the crossing nodes are emptied in the order from far to near.

(2) The empirical formula and algorithm are used to calculate and check in detail, and the driving mode and the detailed structure of the experimental device are obtained in accordance with the requirements of the design of the integrated experimental device. The simulation model of the vacuum collection system enables us to observe the transport characteristics of fluid in the pipeline of the system in practical engineering.

(3) In the design of the vacuum system, the operating parameters of the vacuum equipment or system should be determined according to the nature of the material, the requirements of operation and the degree of vacuum in combination with the actual conditions of the project. This paper compares the specific conditions and operating environment of a Roots vacuum pump and blower in producing a vacuum, calculates and compares the air volume and pressure loss in the pipeline of the system at the farthest node and the most unfavorable situation, and determines the type of negative pressure equipment in the system so that it can ensure the normal operation of the system.

(4) The formula for calculating the saturated vapour pressure of water is adopted $\ln (\mathrm{P})=9.3876-\frac{3826.36}{\mathrm{~T}-45.47}$. The temperature in the pipe is considered to be room temperature. When the temperature in the pipe reaches or exceeds the evaporation temperature under the corresponding saturated vapour pressure, the water is completely evaporated. At this time, the water content in the waste does not need to be considered. If the temperature does not reach the corresponding evaporation temperature under saturated steam pressure, the kitchen waste can be seen as a fluid that is both solid and hydrated. The influence of the existence of liquid phase can be attributed to the physical properties such as solid density, which can avoid the difficulty of analysis and treatment caused by the disturbance of gas to a liquidsolid two-phase mixture.

\section{ACKNOWLEDGEMENTS}

This project is partially supported by the postgraduate innovation engineering project of Jiangsu Province (Grant NO. SJCX19_0616) and Ministry of Industry and Information Technology Large-scale Cruise Project.

\section{REFERENCES}

1. Chen J., et al. (2015): Erosion prediction of liquid-particle two-phase flow in pipeline elbows via CFD-DEM coupling method. Powder Technology, 275, 182-187.

2. Du, J.,Bansal, P.,Huang, B. (2012): Simulation model of a greenhouse with a heat-pipe heating system. Applied Energy, 93(C), 268-276.

3. Du J., Cai Z.,Zhang Y. (2018): Simulation and experimental study of SCR injection system. Polish Maritime Research Special Issue 2018 S2(98) 2018 Vol. 25, 49-55.

4. Du J., Li R., Wu X., Zhang Y. (2018): Study on optimization simulation of SCR denitration system for marine diesel engine. Polish Maritime Research Special Issue 2018 S3(99) 2018 Vol. 25, 13-21.

5. Du, J., Li, R., Wang, H., Wu, X. (2019): Environmental Study on Supercritical CO2 Extraction of Nanocrystalline. Ekoloji, 107(28), 3169-3175.

6. Fernández C.,Manyà F.,Mateu C., et al. (2014): Modeling energy consumption in automated vacuum waste collection systems. Environmental Modelling \& Software, 56, 63-73.

7. Fernández C., Manyà F., Mateu C., Sole-Mauri F. (2015): Approximate dynamic programming for automated vacuum waste collection systems. Environmental Modelling \& Software, 67, 128-137.

8. Fisher C., Meech R. (2013): Bunkers: An analysis of the technical and environmental issues. Petrospot Limited, UK. 
9. Huang S., et al. (2015): Transient numerical simulation for solid-liquid flow in a centrifugal pump by DEM-CFD coupling. Engineering Applications of Computational Fluid Mechanics, 9(1), 411-418.

10. Hong S., Shanshan G., Xiaohui Q, (2018): Thermodynamics analysis of a stratospheric airship with hovering capability. Applied Thermal Engineering, 146, 600-657.

11. Jajcevic D., et al. (2013): Large-scale CFD-DEM simulations of fluidized granular systems. Chemical Engineering Science, 98(29), 298-310.

12. Konstandopoulos A. G., Zarvalis D., Chasapidis L.,et al. (2017): Investigation of SCR Catalysts for Marine Diesel Applications. SAE Int. J. Engines, 10(4) 16530-1666.

13. Levy A. (2010): Modeling of heat transfer in pneumatic conveyer using a combined DEM-CFD numerical code. Drying Technology, 28(2), 155-164.

14. Mohseni M., Peters B. (2016): Effects of particle size distribution on drying characteristics in a drum by XDEM: A case study. Chemical Engineering Science, 152, 689-698.

15. Marigo M., Stitt E. H. (2015): Discrete Element Method (DEM) for Industrial Applications: Comments on Calibration and Validation for the Modelling of Cylindrical Pellets. Kona, 32, 236-252.

16. Patil A. V., et al. (2015): Comparison of CFD-DEM heat transfer simulations with infrared/visual measurements. Chemical Engineering Journal, 277, 388-401.

17. Pan D.,Gu C.,Zhang D.,et al. (2019): Investigation on the relationship between slurry droplet entrainment and fine particle emission in the limestone-gypsum WFGD system. Energy Sources, Part A: Recovery, Utilization, and Environmental Effects (5):1-14.

18. Scherer V., et al. (2016): Coupled DEM-CFD simulation of drying wood chips in a rotary drum-Baffle design and model reduction. Fuel, 184, 896-904.

19. Wang J.,Chia A., Meng H.,et al. (2010): Control of Diesel Engine Urea Selective Catalytic Reduction Systems. Etd. ohiolink.edu, 2010.

20. Zhong W., et al. (2016): DEM/CFD-DEM modelling of nonspherical particulate systems: Theoretical developments and applications. Powder Technology, 302, 108-152.

\section{CONTACT WITH THE AUTHORS}

Du Jun

e-mail:dujun9988@163.com

Jiangsu University of Science and Technology,

No. 2 Mengxi road Jingkou district, 212003 zhenjiang,

CHINA

Li Ruonan

e-mail:876719187@qq.com

Jiangsu University of Science and Technology,

No. 2 Mengxi road Jingkou district, 212003 zhenjiang,

China

Wu Xin

e-mail:1520393531@qq.com

Jiangsu University of Science and Technology,

No. 2 Mengxi road Jingkou district, 212003 zhenjiang,

\section{China}

\section{Zhao Hang}

e-mail:987948095@qq.com

Jiangsu University of Science and Technology,

No. 2 Mengxi road Jingkou district, 212003 zhenjiang,

\section{China}

